\title{
The Population Impact of Late Presentation with Advanced HIV Disease and Delayed Antiretroviral Therapy in Adults Receiving HIV Care in Latin America
}

Pablo F Belaunzarán-Zamudio, Yanink N Caro-Vega, Bryan E Shepherd, Peter F Rebeiro, Brenda E Crabtree-Ramírez, Claudia P Cortes, Beatriz Grinsztejn, Eduardo Gotuzzo, Fernando Mejia, Denis Padgett, Jean W Pape, Vanessa Rouzier, Valdilea Veloso, Sandra Wagner Cardoso, Catherine C McGowan, and Juan G Sierra-Madero, on behalf of the Caribbean, Central and South America network for HIV epidemiology (CCASAnet)

Correspondence to Yanink N Caro Vega, Departamento de Infectología, Instituto Nacional de Ciencias Médicas y Nutrición Salvador Zubirán, Calle Vasco de Quiroga 15 Col Belisario Dominguez Seccion XVI, Tlalpan CP 14080, Mexico City, México (e-mail: yanink.caro@infecto.mx, Phone: +52 55 54870900. Fax:+52 55138106)

Author affiliations: Departamento de Infectología, Instituto Nacional de Ciencias Médicas y Nutrición Salvador Zubirán. Mexico City, Mexico (Pablo F Belaunzarán-Zamudio, Yanink N Caro-Vega, Brenda E Crabtree-Ramírez and Juan G Sierra-Madero); Department of Biostatistics, Vanderbilt University, Nâshville, USA (Bryan E Shepherd); Department of Medicine, Vanderbilt University, Nashyille, USA (Peter F Rebeiro, Catherine C McGowan); Fundación Arriarán, Universídad de Chile, Santiago, Chile (Claudia P Cortes); Instituto de Pesquisa Clínica Evandro Chagas, Fundacão Oswaldo Cruz, Rio de Janeiro, Brazil (Beatriz Grinsztejn, Valdilea V́eloso and Sandra Wagner Cardoso); Instituto de Medicina Tropical Alexander von Humboldt, Lima, Peru (Eduardo Gotuzzo); Instituto Hondureño de Seguridad Social and Hospital Escuela, Tegucigalpa, Honduras (Denis Padgett); Le Groupe Haitien d'Etude du Sareome de Kaposi et des Infections Opportunistes, Port-au-Prince, Haiti (Jean W Pape, Vanessa Rouzier).

(C) The Author(s) 2019. Published by Oxford University Press on behalf of the Johns Hopkins Bloomberg School of Public Health. All rights reserved. For permissions, please e-mail: journals.permissions@oup.com. 
Funding: This work was supported by the NIH-funded Caribbean, Central and South America network for HIV epidemiology (CCASAnet), a member cohort of the International Epidemiologic Databases to Evaluate AIDS (leDEA) (U01AI069923). This award is funded by the following institutes: Eunice Kennedy Shriver National Institute of Child Health and Human Development (NICHD), Office of The Director, National Institutes of Health (OD), National Institute of Allergy and Infectious Diseases (NIAID), National Cancer Institute (ACI), and the National Institute of Mental Health (NIMH).

Conflict of Interest Disclosures: Pablo F Belaunzaran-Zamudio, Yanink N Caro-Vega, Bryan E Shepherd, Brenda E Crabtree-Ramírez, Claudia P Cortes, Denis Padgett and Peter F Rebeiro, Beatriz Grinsztejn, Eduardo Gotuzzo, Fernando Mejia, Denis Padgett, Jean W Pape, Vanessa Rouzier, Valdilea Veloso and Sandra Wagner Cardoso have no conflicts of interest to declare. Catherine C McGowan reports grants from the US NIH. Dr. Sierra-Madero reports personal fees and non-financial support from Gilead, non-financial support from MSD, grants from BMS, grants from Pfizer, personal fees from Jansen all outside the submitted work.

Running Head: Population impact of Late Presentation to HIV care 


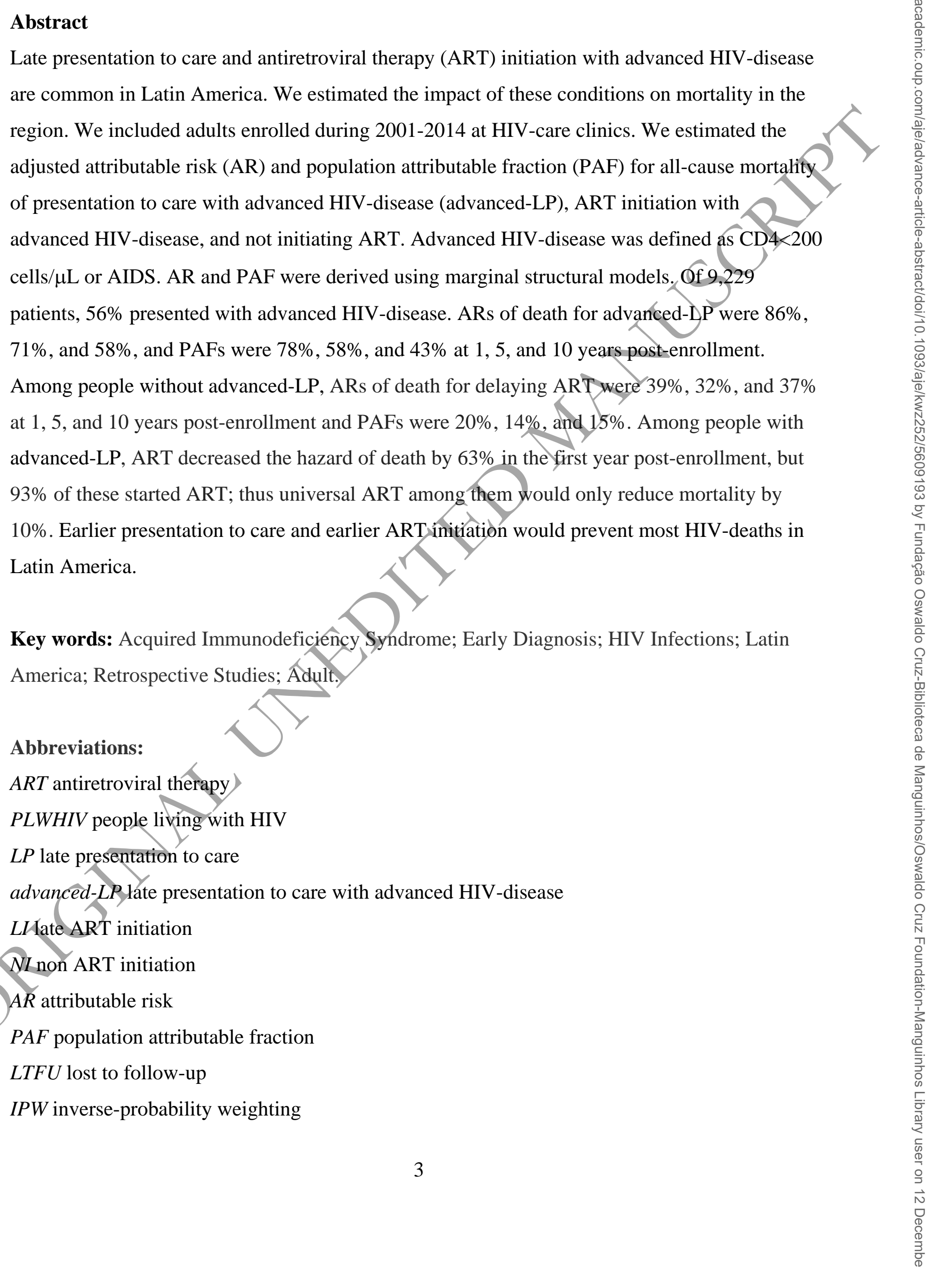


The use of combined antiretroviral therapy (ART) after 1996 was followed by an abrupt reduction in AIDS mortality (1), though this was less dramatic in low- and middle-income countries after the expansion of access to ART (2). Particularly, mortality remains high in most of Latin America (3-6). While the lower-than-expected impact of improved ART access on mortality in our region has been attributed to the frequency of late HIV-diagnosis and ART initiation (7), no formal assessment of the population impact of these factors on mortality has been performed.

People living with HIV (PLWHIV) starting ART in resource-poor settings have higher mortality during the first months on therapy than those in high-income countries. Advanced immunosuppression when starting ART is the main factor associated with these differences (810). In Latin America 37\% to $76 \%$ of patients initiate ART with CD4 counts $<200$ cells $/ \mu \mathrm{L}$ $(11,12)$, and late ART initiation is thought to be the main determinant of mortality (13). Previous analyses, however, only considered patients starting ART, although a high proportion of deaths may occur before ART initiation (14). Here, we aimed to estimate the potential impact that eliminating presentation to care and starting ART with advanced HIV-disease would have on mortality among adults with HWV in Latin America. Using the Caribbean, Central and South America network for HIy epidemiology (CCASAnet) cohort, we estimated the proportion of deaths attributable to late presentation to care with advanced HIV-disease (advanced-LP), initiating ART in this stage (LI), and the impact of failing to initiate ART (NI) in people with advanced-LP. As measures of impact, we estimated the proportion of all deaths among people with advanced-LP and among the entire study population that could have been prevented by earlier presentation (i.e., the attributable risk (AR) and population attributable fraction (PAF), respectively, of advanced-LP on mortality). Similar measures were used to estimate the impact 
of LI and NI. Both the AR and the PAF are relevant to public health and consider not only the magnitude of association between exposure and outcome, but also the frequency of the exposure in the population. The rationale for this study is to quantify the potential public health benefit of implementing strategies that reduce late diagnosis/linkage to care and reduce time to ART initiation.

\section{METHODS}

Study design, cohort description and analytical approach

We used clinical data from PLWHIV receiving care in six centers of CCASAnet: Fundación Huésped in Buenos Aires (FH-Argentina), Instituto de Pesquísa Clínica Evandro Chagas, Fundacão Oswaldo Cruz in Rio de Janeiro (FC-Brazil), Fundación Arriarán in Santiago (FAChile), Instituto Hondureño de Seguridad Social and Hospital Escuela in Tegucigalpa (IHSS/HEHonduras), Instituto Nacional de Ciencłas Médicas y Nutrición Salvador Zubirán in Mexico City (INCMNSZ-Mexico), and Instituto de Medicina Tropical Alexander von Humboldt in Lima (IMTAvH- Peru) (15). We included all ART-naïve adults ( $\geq 18$ years), enrolled in care between January $1^{\text {st }}, 2001$ and December $31^{\text {st }}, 2014$, with a recorded CD4 count between 360 days before and 90 days after enrollment.

We performed three sets of analyses: first, we estimated the impact of advanced-LP on mortality in the whole cohort, regardless of ART initiation; second, we estimated the impact of LI among those who presented without advanced-LP; and third, we estimated the impact of NI among people with advanced-LP. 


\section{Outcomes and definitions}

The primary endpoint was all-cause mortality. Methods for mortality ascertainment differed by cohort site with varying levels of patient tracing and/or linkage to national death registries (13). We defined LP as enrollment in participating centers having AIDS or a CD4 count $<350$ cells $/ \mu \mathrm{L}$ and advanced HIV-disease as having AIDS or a CD4 count $<200$ cells/ $\mu \mathrm{L}$ (16). Patients were classified accordingly as LP with advanced HIV-disease, (advanced-LP), and LI if starting ART with advanced HIV-disease. Patients enrolled with advanced-LP that did not start ART were defined as NI. We did our primary analysis based on the impact of advanced-LP and LI. In secondary analysis, we assessed the impact of LP and late ART initiation (16). AIDS was defined using CDC or WHO criteria (any stage C or WHO 4 category). Patients whose last visit occurred more than one year before cohort closure were considered lost to follow-up (LTFU) and their data were censored at their last visit date; otherwise, individuals were followed until death or administrative censoring. Analyses assessed the impact of starting ART on mortality; any information on non-adherence or discontinuation of ART after ART initiation was not included

\section{Statistical analysis}

The AR of mortality due to exposure (advanced-LP, advanced-LI among patients without advanced-LP, and NI among those with advanced-LP) was computed as the difference in the estimated probabilities of death between exposed and non-exposed divided by the probability of death in the exposed. Hence, the AR estimates can be interpreted as the proportion of deaths among people with the exposure that can be attributed to the exposure itself, or as the proportion of deaths that could had been averted had there been no exposure (17). The PAF of exposure on mortality was estimated using Miettinen's formula (18). The PAF may be interpreted as the 
proportion of deaths in the entire study population that would have been prevented had exposed patients not been exposed. We used inverse-probability weighting (IPW) methods to correct for potential selection biases (19).

Specifically, to assess the impact of advanced-LP on mortality, we estimated probabilities of mortality after enrollment for all participants in the cohort using IPW Kaplan-Meier estimates. IPW for advanced-LP were constructed including study site, enrollment date, sex, and age using logistic regression. Age and enrollment date were included in the model using restricted cubic splines with 5 knots, with the number of knots selected as explained in the supplementary material (20). We computed the adjusted AR and PAF of death due to advanced-LP from the IPW Kaplan-Meier estimates of survival comparing patients with and without advanced-LP. We computed confidence intervals (CI) using bootstrap techniques with 200 replications.

In the second analysis, among patients without advanced-LP, we estimated the impact of failing to start ART before having advanced HIV-disease; therefore, we included only patients who presented to care with $\mathrm{CD} 4 \geq 200$ cells $/ \mu \mathrm{L}$ and without AIDS. We used a dynamic marginal structural model to estimate probabilities of mortality over time based on different treatment initiation conditions to correct selection biases arising from lack of randomization to time of treatment initiation $(19,21)$. We compared the following treatment initiation conditions 1) start ART at a non-advanced disease stage (CD4 $\geq 200$ cells $/ \mu \mathrm{L}$ and no AIDS) versus 2) start ART at an advanced HIV-disease stage (CD4 $<200$ cells $/ \mu \mathrm{L}$ or AIDS) [advanced-LI]). This analysis was conducted using exposure-time in each condition, such that patients contributed follow-up time to the treatment initiation condition with which their data were consistent, and patients were 
artificially censored from specific treatment conditions when their data no longer were consistent with the condition (e.g., if someone started ART prior to being in an advanced HIV-disease stage, the patient would be censored from condition 2 at the time of ART initiation; when someone entered an advanced stage without having started ART, they were censored from condition 1). Pooled logistic regression (i.e., a discrete time survival model) was used to estimate the mortality hazard ratio of deferring therapy. The pooled logistic regression model included time (expanded using restricted cubic splines with 4 knots) and was weighted by the inverse probability of not being censored (artificially or otherwise) at a given time point. Prior to ART initiation or progression to advanced HIV-disease, the probábility of not being artificially censored was set as the inverse of the estimated cumulative probability of not starting ART for patients in the advanced-LI group. For patients in the not advanced-LI group who had not yet started ART, this was set as the inverse of the estimated cumulative probability of not entering advanced HIV-disease. The probability of starting ART was estimated for those who had not yet started ART using pooled logistic regression including time from enrollment, year of enrollment, most recent $\mathrm{CD} 4$, time since most recent CD4 measurement, age at enrollment, study site, and sex; continuous covariates were expanded using restricted cubic splines with 4 knots. The probability of progressing to advanced HIV-disease was estimated among those who had not started ART. The predicted survival probability for those in the advanced-LI and not advancedLI groups were estimated using a similar model, except including an interaction between time from enrollment and treatment condition. In all models, we used $\log ($ time) and selected the number of knots as described above (20). ARs and PAFs of mortality for LI and their corresponding $95 \% \mathrm{CI}$ were calculated as previously explained, from the estimated probabilities of death by treatment initiation condition, derived from the dynamic marginal structural model. 
In the third analysis we assessed the impact of not initiating ART (NI) among advanced-LP. The goal was to compare the probability of mortality over time among advanced-LP for immediately starting ART versus never starting ART. We fit a standard marginal structural model (22), where the exposure was starting ART. We adjusted for the same covariates described above in our second analysis. The AR and PAF were computed using estimates of the probabilities of mortality predicted from the fitted marginal structural model and CIs were computed using the bootstrap with 200 replications. All primary analyses winsorized IPW at the $2.5^{\text {th }}$ and $97.5^{\text {th }}$ percentiles; sensitivity analyses considered other percentiles.

In secondary analyses, we computed the population impact of advanced-LP on mortality under a more plausible scenario of reducing advanced-LP by approximately $50 \%$. In this calculation, we used the distribution of advanced-LP in the study population, the magnitude of the association between advanced-LP and death derived from the weighted Kaplan-Meier estimates, and the expected attainable reduction of advanced-LP under normal programmatic conditions (23). We chose an attainable $50 \%$ reduction to achieve a prevalence of advanced-LP of approximately $30 \%$, as this is close to the overall prevalence reported in Europe (24). We also repeated each set of analyses using CD4 count $<350$ cells/ $\mu \mathrm{L}$ or AIDS to define late presentation to care (LP) and late treatment initiation (LI) in people presenting early to care. We computed e-values to assess sensitivity of results to unmeasured confounding (25). We also repeated analyses excluding data from INCMNSZ-Mexico because for most of the analysis period, this site captured data only after patients were started on ART. Analyses were performed in Mexico and the Data Coordinating Center in USA using R Statistical Software version 1.2.1335 (www.R-project.org, 
Boston, MA). Analysis scripts are available online

(biostat.mc.vanderbilt.edu/ArchivedAnalyses).

\section{Ethical considerations}

Institutional ethics review boards from each participating site and the data coordinating center reviewed and approved procedures. We followed the principles outlined in the Declaration of Helsinki by the 41st World Medical Assembly.

\section{RESULTS}

\section{Baseline characteristics}

We included 9,229 patients enrolled in care in six CCASAnet centers between 2001 and 2014 (Table 1). Median age at enrollment was 34 years $\left(25^{\text {th }}\right.$ and $75^{\text {th }}$ percentiles 28 and 42 years $)$ and $75 \%$ were men. Median CD4 at enrollment was 198 cells $/ \mu \mathrm{L}\left(25^{\text {th }}\right.$ and $75^{\text {th }}$ percentiles 68 and 381 cells $/ \mu \mathrm{L})$. Patients were followed for a median of 4 years $\left(25^{\text {th }}\right.$ and $75^{\text {th }}$ percentiles 1 and 7 years). Sociodemographic and clinical characteristics at enrollment by exposure group are summarized in supplementary materials (Web Table 1).

Frequency of advanced-LP, advanced-LI and NI

There were 5,162 (56\%) patients with advanced-LP, of which 93\% started ART. Among 4,067 patients without advanced-LP, 3,119 (77\%) started ART, 82\% (n=2,571) while they were asymptomatic with CD4 $\geq 200$ cells/ $\mu \mathrm{L}$ (Figure 1). Sex, age, site and year at enrollment were all independently associated to advanced LP (See Web Table 2 in supplementary materials) 


\section{Mortality}

Seven hundred (7.6\%) patients died during the study period. There were 1,717(19\%) patients LTFU. Figure 1 shows the proportion of deaths according to stage at enrollment and ART initiation. Figure 2 shows the weighted survival probabilities and hazard ratios after enrollment for people with advanced-LP compared to those without advanced-LP (Figure 2, A); for advanced-LI versus non advanced-LI among those without advanced-LP (Figure 2, B); and NI in people with advanced-LP compared to those that initiated ART (Figure 2, C).

Potentially averted deaths if advanced-LP, advanced-LI, and NI were eliminated

The AR and PAF of mortality for advanced-LP, advanced-LI among people without advancedLP, and NI among advanced-LP are shown in Table 2. We estimated that eliminating advancedLP would have prevented $86 \%, 71 \%$, and $58 \%$ of deaths at 1,5 , and 10 years after enrollment, respectively, among those enrolled with advanced HIV-disease and 78\%, 58\%, and $43 \%$ of all deaths. In secondary analysis, we estimated that reducing advanced-LP from $56 \%$ to $30 \%$, would had prevented $66 \%$ (95\% CI: $54 \%, 77 \%$ ) of all deaths occurring in the first year after enrollment, $42 \%$ (95\% CI: $34 \%, 51 \%)$ of deaths in the first 5 years, and 29\% (95\%CI: $20 \%, 38 \%)$ of deaths in the first 10 years.

Among people withøut advanced-LP, ARs of death for delaying ART were 39\%, 32\%, and 37\% at 1, 5, and 10 years post-enrollment and PAFs were 20\%, 14\%, and 15\%. Among people with advanced-LP, ART decreased the hazard of death by $63 \%$ in the first year post-enrollment, but 93\% of these started ART; thus universal ART among them would only reduce mortality by $10 \%$. 
Secondary analysis and sensitivity analysis

We observed very similar results when estimating the impact of LP to care (CD4 $<350$ cells $/ \mu \mathrm{L}$ or AIDS at enrollment), delaying ART initiation (LI) among non-LP, and not initiating ART among LP (Web Table 3). These results are presented in supplementary materials (see Web Figures 1-4). Our results were robust to the choice of winsorization level for the IPW. We observed no changes when excluding INCMNSZ-Mexico from analyses. The estimated e-value for our advanced-LP analysis was 6.12, meaning that an unmeasured confounder with an association with both advanced-LP and death with a Risk Ratio of at least 6.12 (for the point estimate to be 1) or 5.33 (for the upper limit of the $95 \% \mathrm{CI}$ to include 1) would be needed to explain away the observed HR. The e-values for the association between advanced-LI and death were 2.5 for the point estimate and 1.36 for the upper limit of the $95 \%$ CI. E-values for the association between NI and death were 4.84 for the point estimate and 3.18 for the $95 \% \mathrm{CI}$ to include 1.

\section{DISCUSSION}

Using model-based ARs and PAFs of mortality in a multinational observational cohort in Latin America, we found that during the first year after enrollment, $86 \%$ of deaths occurring among people with advanced-LP and 78\% of deaths in the entire cohort could have been prevented by eliminating advanced-LP, which occurred in $56 \%$ of patients. Even reducing advanced-LP to the møre plausibly obtainable goal of $30 \%$, would eliminate approximately two-thirds of all deaths occurring during the first year of enrollment. Starting ART before advanced disease in all patients presenting with non-advanced HIV-disease would have prevented a lower proportion of 
deaths (39\% among advanced-LI, and 20\% among all non-LP the first year in care). Finally, starting ART in all patients with advanced-LP would have prevented $66 \%$ of deaths during the first year after enrollment in NI, but only $10 \%$ of deaths among all patients with advanced-LP. The implications of our results are better understood when considering that around 850000 people died due to AIDS in Latin America during this period (26). Our results suggest that the absolute number of HIV-related deaths that could have been prevented in Latin America by reducing advanced-LP is likely in the hundreds of thousands, and more importantly, tens of thousands of annual deaths could be prevented in the next decade by reducing advanced-LP and by initiating ART in all adults with HIV. The estimated PAFs for mortality of advanced-LP were particularly high due to the high frequency of this condition. The benefits of starting ART earlier for people who enroll in care without advanced disease are also apparent, though not as striking, due in part to the low frequency of early presentation, an already relatively high frequency of ART initiation, and lower mortality risk in these patients. Even so, a quarter of all deaths over ten years among people without advanced-LP would have been averted had they all started ART before progressing to advanced HIV-disease. In contrast, not starting ART for people with advanced-LP entailed a very high short- and long-term mortality, but the estimated PAF was low because most of them did start ART. In the present context of guidelines to treat all adults with HIV (27), the goals of eliminating all LI in not-advanced-LP and NI in all advanced-LP should by all rights be attained immediately, though the goal of rapid ART initiation in all populations faces challenges.

These findings contribute to the knowledge of a previously well documented problem in our region, namely presentation with advanced HIV-disease $(11,12,28)$ and late ART initiation, $(11,29,30)$ by quantifying their population impact on AIDS-related mortality in Latin America. A 
skeptic might suggest that presentation to care and ART initiation with advanced HIV-disease are already known to impact patient mortality, and that these results are largely confirmatory. However, quantification of the population impact of these phenomena in Latin America is important to demonstrate the magnitude of the problem. Our results also help to identify the potential impact of reducing gaps in the continuum of care for PLWHIV in the region. While previous studies by our group and others had focused on the survival of PLWHIV starting ART (13), measures of association by themselves are insufficient to determine public health impacts. Our results show that most deaths among PLWHIV in our region can beprevented with the implementation of evidence-based, effective, and available strategies to reduce the proportions of undiagnosed people, improve linkage to care, and increase ART use. In British Columbia, widespread HIV screening increased the proportion of PLWHIV diagnosed at earlier stages and effectively reduced the incidence of AIDS-defining event, all-cause mortality, and the proportion of deaths from AIDS-related causes (1,31). Expansion of testing services, including routine HIVcare testing for all patients receiving emergency care (32), community-based and home-based testing $(33,34)$, supervised or unsupervised self-testing (35), and targeted testing of high-risk groups (36) have all improved early diagnosis and ART initiation in regions with concentrated epidemics, such as ours. Similarly, large-scale interventions to reduce time between diagnosis and enrollment in care, such as point-of-care technology (37), peer-navigator programs (38) and home-based initiation of care (39) have successfully increased enrollment in care and reduced time to ART initiation in other settings. These same interventions would help identify people who die before HIV-diagnosis or enrollment in care, which are not included in this cohort and suggest we may be under-estimating the impact of eliminating advanced-LP. 
Of note, we employed modern causal inference techniques incorporating IPW to obtain properly adjusted estimates of the AR and PAF. Despite the propriety of the AR and PAF for measuring the population impact of a risk factor and recent developments in their use (40-42), we have not seen these measures used in conjunction with methods that permit the inclusion of time-varying confounders or the comparison of dynamic treatment strategies. Our application of dynamic marginal structural model to estimate the AR and PAF of late ART initiation on mortality is methodologically innovative. That said, the limited number of centers contributing information and the characteristics of these centers may limit the generalizability of our estimates. Nonetheless, our results are in agreement with previous studies about late HIV-diagnosis $(7,11,28), \mathrm{LP}(11,12,28)$ and LI $(29,30)$ in Latin America.

Potential limitations of the study are the aggregated estimates that may obscure heterogeneity across the region. In addition, because $75 \%$ of the study population was enrolled before 2011, our results might not be applicable to people enrolled in care recently, particularly in an era of universal-treatment guidelines. Howeve, quantification of the potential impact of earlier enrollment in care and earlier ART initiation in the past can be used to motivate better policy and implementation in the future, in particular in our region, where the frequency of late diagnosis and mortality has overall remained constant. We did not have cause of death information. As with all observational studies, there could be confounding variables that were not accounted for in our analyses. High e-values obtained in sensitivity analyses suggest that important unmeasured confounders (e.g., drug use) are unlikely to explain away the associations between exposures and mortality $(45,46)$, although they could alter AR and PAF estimates. Finally, some of our study sites had high rates of LTFU that might have biased our estimates towards a reduction in the magnitude of the impact of advanced-LP and advanced-LI, considering that 
these are associated with higher rates of LTFU [13] and people LTFU are typically more likely to die than those remaining in care (44).

In conclusion, the majority of deaths among PLWHIV in Latin America are attributable to advanced-LP, and to a lesser extent to delaying ART initiation. Earlier presentation to care, and earlier initiation of ART after enrollment would substantially reduce mortality among PLWHIV in Latin America, mainly during the first year after enrollment in care, but even ten years later. Our results show that most deaths among PLWHIV in our region are preventable using existing, evidence-based, effective interventions to improve early diagnosis, linkage to care, and early ART initiation.

\section{SUPPLEMENTARY DATA}

Available at AJE online.

\section{Acknowledgments}

Author affiliations: Departamento de Infectología, Instituto Nacional de Ciencias Médicas y Nutrición Salvador Zubirán. Mexico City, Mexico (Pablo F Belaunzarán-Zamudio, Yanink N Caro-Vega, Brenda E Crabtree-Ramírez, Juan G Sierra-Madero); Department of Biostatistics, Vanderbilt UniYersity School of Medicine, Nashville, Tennessee (Bryan E Shepherd, Peter F Rebeiro); Department of Medicine, Vanderbilt University School of Medicine, Nashville,

Tennessee (Peter F Rebeiro, Catherine C McGowan); Fundación Arriarán, Universidad de Chile,

Santiago, Chile (Claudia P Cortes); Instituto de Pesquisa Clínica Evandro Chagas, Fundacão

Oswaldo Cruz, Rio de Janeiro, Brazil (Beatriz Grinsztejn, Valdilea Veloso, Sandra Wagner

Cardoso); Instituto de Medicina Tropical Alexander von Humboldt, Lima, Peru (Eduardo 
Gotuzzo, Fernando Mejia); Instituto Hondureño de Seguridad Social and Hospital Escuela, Tegucigalpa, Honduras (Denis Padgett); Le Groupe Haitien d'Etude du Sarcome de Kaposi et des Infections Opportunistes, Port-au-Prince, Haiti (Jean W Pape, Vanessa Rouzier)

Financial support: This work was supported by the NIH-funded Caribbean, Central and South America network for HIV epidemiology (CCASAnet), a member cohort of the International Epidemiologic Databases to Evaluate AIDS (leDEA) (U01AI069923). This âward is funded by the following institutes: Eunice Kennedy Shriver National Institute of Child Health \& Human Development (NICHD), National Cancer Institute (NCI), Nationál Institute of Allergy and Infectious Diseases (NIAID), National Institute of Mental Health (NIMH), and the Office of The Director, National Institutes of Health (OD). The sponsors had no role in the design and conduct of the study; no role in the collection, analysis, and interpretation of the data; nor in the preparation, review, or approval of the manuscript or decision to submit.

The Caribbean, Central and South America Network for HIV Epidemiology (CCASAnet) includes the following sites and staff: Fundación Huesped, Argentina: Pedro Cahn, Carina Cesar, Valeria Fink, Omar Sued, Patricia Patterson, Emanuel Dell'Isola, Hector Perez, Jose Valiente, Cleyton Yamamoto.Instituto Nacional de Infectologia-Fiocruz, Brazil: Beatriz Grinsztejn, Valdilea Veloso, Paula Luz, Raquel de Boni, Sandra Cardoso Wagner, Ruth Friedman, Ronaldo Moreira. Universidade Federal de Minas Gerais, Brazil: Jorge Pinto, Flavia Ferreira, Marcelle Maia. Universidade Federal de São Paulo, Brazil: Regina CeÂlia de Menezes Succi, Daisy Maria Machado, Aida de Fátima Barbosa Gouvêa. Fundación Arriarán, Chile: Marcelo Wolff, Claudia P. Cortes, Maria Fernanda Rodriguez, Gladys 
Allende. Les Centres GHESKIO, Haiti: Jean William Pape, Vanessa Rouzier, Adias Marcelin, Christian Perodin. Hospital Escuela Universitario, Honduras: Marco Tulio Luque. Instituto Hondureño de Seguridad Social, Honduras: Denis Padgett. Instituto Nacional de Ciencias Médicas y Nutrición Salvador Zubirán, México: Juan Sierra Madero, Brenda Crabtree-Ramirez, Pablo F. Belaunzarán-Zamudio, Yanink Caro-Vega and Rocío Velázquez Pastrana. Instituto de Medicina Tropical Alexander von Humboldt, Peru: Eduardo Gotuzzo, Fernando-Mejia, Gabriela Carriquiry. Vanderbilt University Medical Center, USA: Catherine C McGowan, Bryan E Shepherd, Timothy Sterling, Karu Jayathilake, Anna K Person, Peter F Rebeiro, Jessica Castilho, Stephany N Duda, Fernanda Maruri, Hilary Vansell, Sally Bebawy and James Logan.

Previous presentations: Preliminary results presented at the Glasgow HIV Therapy 2016 in Glasgow, October 23-27, 2016 (Abstract P340) and at the $22^{\text {nd }}$ International Workshop on HIV and Hepatitis Observational Databases (IWHOD) in Fuengirola Spain, March 22-24, 2018

Conflicts of interest statement: Pablo F Belaunzaran-Zamudio, Yanink N Caro-Vega, Bryan E Shepherd, Brenda ECrabtree-Ramírez, Claudia P Cortes, Denis Padgett and Peter F Rebeiro, Beatriz Grinsztejn, Eduardo Gotuzzo, Fernando Mejia, Denis Padgett, Jean W Pape, Vanessa Rouzier, Valdilea Veloso and Sandra Wagner Cardoso have no conflicts of interest to declare.

Catheríne C McGowan reports grants from the US NIH. Dr. Sierra-Madero reports personal fees and non-financial support from Gilead, non-financial support from MSD, grants from BMS, grants from Pfizer, personal fees from Jansen all outside the submitted work. 


\section{REFERENCES}

1. Lima VD, Lourenço L, Yip B, et al. AIDS incidence and AIDS-related mortality in British

Columbia, Canada, between 1981 and 2013: a retrospective study. Lancet HIV. 2015; 2(3): e92e97

2. UNAIDS. AIDSinfo Online Database [Internet]. Geneva; 2015 [cited August $8^{\text {th }} 2016$ ]. Available at: http://www.aidsinfoonline.org/devinfo/libraries/aspx/dataview.aspx\# Accessed August 15, 2017.

3. Hernández-Ávila JE, Palacio-Mejía LS, Hernández-Romieu A, et al. Effect of Universal Access to Antiretroviral Therapy on HIV/AIDS Mortality in Mexico 1990-2011. J Acquir Immune Defic Syndr. 2015;69(3):e100-e108

4. Joint United Nations Programme on HIV/AIDS.(UNAIDS). The Gap Report 2014. UNAIDS / JC2656 (English original, July 2014, updated September 2014). ISBN 978-92-9253062-4. Available at: http://www.unaids.org/en/resources/campaigns/2014/2014gapreport/slides/ Accessed August 15, 2017.

5. Ministerio de Salud de la Nación. Dirección de Sida y ETS. Boletín Epidemiológico sobre VIH-sida e ITS en la Argentina.Buenos Aires, Argentina: Dirección de Sida y ETS; 2014 (Boletín Epidemiológico sóbre VIH-sida e ITS, no. 31. Año XVII. Diciembre). Available at: http://www.msal.gob.ar/sida/index.php/publicaciones/boletines-epidemiologicos. Accessed October 9th, 2019.

6. Ministerio de Salud y Protección Social. Informe Nacional GARPR - 2014. Bogotá, Colombia: Ministerio de Salud y Protección Social; 2014. (Seguimiento de la Declaración de compromiso sobre el VIH/sida. Abril del 2014). Available at: 
https://www.unaids.org/sites/default/files/country/documents/COL_narrative_report_2014.pdf. Accessed October 9th, 2019.

7. Crabtree-Ramírez B, Caro-Vega Y, Belaunzarán-Zamudio F, et al. High prevalence of late diagnosis of HIV in Mexico during the HAART era. Salud Publica Mex. 2012; 54(5): 506-514.

8. The Antiretroviral Therapy in Lower Income Countries (ART-LINC) Collaboration and ART Cohort Collaboration (ART-CC) groups. Mortality of HIV-1-infected patients in the first Year of antiretroviral therapy: comparison between low-income and high-income countries. Lancet. 2006; 367(9513): 817-824

9. Grinsztejn B, Veloso VG, Friedman RK, et al. Early mortality and cause of deaths in patients using HAART in Brazil and the United States. AIDS. 2009; 23(16): 2107-2114.

10. Luz PM, Bruyand M, Ribeiro S, et al. AIDS and non-AIDS severe morbidity associated with hospitalizations among HIV-infected patients in two regions with universal access to care and antiretroviral therapy, France and Brazil,2000-2008: hospital-based cohort studies. BMC Infect Dis. 2014; 14:278

11. Crabtree-Ramírez B, Caro-Vega Y, Shepherd BE, et al. Cross-Sectional Analysis of Late HAART Initiation in Latin America and the Caribbean: Late Testers and Late Presenters. PLoS ONE. 2011;6(5): e20272.

12. Belaunzarán-Zamudio $\mathrm{P}$, Zitko $\mathrm{P}$, Araúz Rodríguez A, et al. Modest progress in early linkage to care in Latin American HIV-care centres from the HIV Latin American Workshop Group (2013-2017) [abstract P044]. Presented at the HIV \& Hepatitis in the Americas 2019, Bogotá, Colombia, April 4-6, 2019. 
13. Carriquiry G, Fink V, Koethe JR, et al. Mortality and loss to follow-up among HIV-infected persons on long-term antiretroviral therapy in Latin America and the Caribbean. J Int AIDS Soc. $2015 ; 18: 20016$.

14. Martín-Onraet A, Piñeirúa-Menéndez A, Perales-Martínez D, et al. Mortalidad hospitalaria en pacientes con infección por VIH: a diez años del acceso universal a TARAA en Méxíco. Salud Pub Mex. 2015;57(supl 2): S163-S170.

15. McGowan CC, Cahn P, Gotuzzo E, et al. Cohort profile: Caribbean, Central and South America Network for HIV research (CCASAnet) collaboration within the International Epidemiologic Databases to Evaluate AIDS (IeDEA) programme Int J Epidemiol. 2007;36(5):969-976.

16. Antinori A, Coenen T, Costagiola $\mathrm{D}$, et al. Late presentation of HIV infection: a consensus definition. HIV Med. 2011 Jan;12(1):61-4.

17. Walter SD. The Estimation and Interpretation of Attributable Risk in Health Research. Biometrics. 1976;32(4):829-849

18. Miettinen, O. Proportion of disease caused or prevented by a given exposure, trait or intervention. Am J Epidemiol. 1974;99(5):325-332.

19. Hernán MA, Lanoy E, Costagliola D, et al. Comparison of dynamic treatment regimes via inverse probability weighting. Basic Clin Pharmacol Toxicol. 2006;98(3):237-242.

20. Frank E. Harrell Jr. Regression Modeling Strategies with Applications to Linear Models, Logistic and Ordinal Regression, and Survival Analysis. Second Edition. Springer, ISSN 01727397 ISSN 2197-568X (electronic) Springer Series in Statistics. ISBN 978-3-319-19424-0 ISBN 978-3-319-19425-7 (eBook) 
21. Cain LE, Robins JM, Lanoy E, et al. When to start treatment? A systematic approach to the comparison of dynamic regimes using observational data. Int J Biostat. 2010;6(2): Article 18.

22. Hernán MA, Brumback B, Robins JM. Marginal structural models to estimate the causal effect of zidovudine on the survival of HIV positive men. Epidemiology. 2000;11(5):561-570.

23. Morgenstern H, Bursic ES. A method for using epidemiologic data to estimate the potential impact of an intervention on the health status of a target population. J Community Health. 1982 Summer;7(4):292-309.

24. Late presenters working group in COHERE in EuroCoord, Mocroft A, Lundgren J, Antinori A, et al. Late presentation for HIV care across Europe: update from the Collaboration of Observational HIV Epidemiological Research Europe (COHERE) study, 2010 to 2013. Euro Surveill. 2015;20(47). doi: 10.2807/1560-7917.ES.2015.20.47.30070.

25. Haneuse S, VanderWeele TJ, Arterburn D, Using the E-Value to Assess the Potential Effect of Unmeasured Confounding in Observational Studies. JAMA. 2019;321(6):602-603.

26. UNAIDS. Joint United Nations Programme on HIV/AIDS. AIDSinfo. AIDS-related deaths. Latin America. UNIAIDS Estimates 2018. Available at: http://aidsinfo.unaids.org/\# 27. Consolidated Guidelines on the Use of Antiretroviral Drugs for Treating and Preventing HIV Infection: Recommendations for a Public Health Approach. 2nd edition. Geneva: World Health Organization; 2016. Available from: https://www.who.int/hiv/pub/arv/arv-2016/en/ Accessed August 10, 2017

28. Bianchetti Valentini M, Guerra de Toledo ML, Oliveira Fonseca M, et al. Evaluation of late presentation for HIV treatment in a reference center in Belo Horizonte, Southeastern Brazil, from 2008 to 2010. Braz J Infect Dis. 2015;19(3):253-262 
29. Warley E, Fernández-Galimberti G, Vieni MI, et al. Factores asociados al estadio clínico avanzado en el inicio de la terapia antirretroviral. Medicina. 2012;72(5):367-370.

30. Magis-Rodríguez CL, Villafuerte-García A, Cruz-Flores RA, et al. Inicio tardío de terapia antirretroviral en México. Salud Pub Mex. 2015;57(suppl 2):S127-S134.

31. Cheung CC, Ding E, Sereda P, et al. Reductions in all-cause and cause-specific mortality among HIV-infected individuals receiving antiretroviral therapy in British Columbia, Canada: 2001-2012. HIV Med. 2016;17(9): 694-701

32. Mosqueda JL, León-Guerrero EM, Álvarez J, et al. Improving earlyHIV diagnosis by increasing HIV testing: experience in León, Guanajuato, Mexico (Abstract P014) J Int AIDS Soc. 2015; 18 (Suppl 2): p16

33. Suthar AB, Ford N, Bachanas PJ, et al. Towards Universal Voluntary HIV Testing and Counselling: A Systematic Review and Meta-Analysis of Community-Based Approaches. PLoS Med. 2013; 10(8): e1001496.

34. Bigogo G, Amolloh M, Laserson KF, et al. The impact of home-based HIV counseling and testing on care-seeking and incidence of common infectious disease syndromes in rural western Kenya. BMC Infect Dis. 2014; 14:376.

35. Pant Pai N, Sharma J, Shivkumar S, et al. Supervised and unsupervised self-testing for HIV in high- and low-risk populations: a systematic review. PLoS Med. 2013;10(4): e1001414.

36. Ruiz Y, Medina Y, Iracheta P, et al. HIV/STI testing among MARPs in Mexico City: a key first step to improve the cascade of care. J Int AIDS Soc. 2016; 19(Suppl 1): p18

37. Jani IV, Sitoe NE, Alfai ER, et al. Effect of point-of-care CD4 cell count tests on retention of patients and rates of antiretroviral therapy initiation in primary health clinics: an observational cohort study. Lancet. 2011;378(9802): 1572-1579 
38. Govindasamy D, Meghij J, Kebede Negussi E, et al. Interventions to improve or facilitate linkage to or retention in pre-ART (HIV) care and initiation of ART in low- and middle-income settings--a systematic review. J Int AIDS Soc. 2014 Aug 1; 17:19032.

39. MacPherson P, Lalloo DG, Webb EL, et al. Effect of optional home initiation of HIV care following HIV self-testing on antiretroviral therapy initiation among adults in Malawi: a randomized clinical trial. JAMA. 2014;312(4):372-379.

40. Cox C. Model-based estimation of the attributable risk in case-control and cohort studies. Stat Methods Med Res. 2006;15(6):611-625.

41. Chen YQ, Hu C, Wang Y. Attributable risk function in the proportional hazards model for censored time-to-event. Biostatistics. 2006.7(4): 515-529.

42. Lin H, Allore HG, McAvay G, et al. A Method for Partitioning the Attributable Fraction of Multiple Time-Dependent Coexisting Risk Factors for an Adverse Health Outcome. Am Journal Pub Health. 2013;103(1):107-182.

43. Diego-Diaz S, Caro-Vega Y, Carrasco-Hernández R, et al. Causes of mortality and time to death in people living with HIV in Mexico City (Abstract P005). J Int AIDS Soc. 2016(suppl 2):p12.

44. Teixeira da Silva DS, Luz PM, Lake JE, et al. Poor retention in early care increases risk of mortality in a Brazilian HIV-infected clinical cohort. AIDS Care. 2017;29(2):263-267.

45. Opde, Coul EL, van Sighem A, Brinkman K, et al. Factors associated with presenting late or with advanced HIV disease in the Netherlands, 1996-2014: results from a national observational cohort. BMJ Open. 2016 Jan 4;6(1): e009688. 
46. Jiang H, Xie N, Fan Y, et al. Risk Factors for Advanced HIV Disease and Late Entry to HIV Care: National 1994-2012 HIV Surveillance Data for Wuhan, China. AIDS Patient Care STDS. 2015 Oct;29(10):541-9.

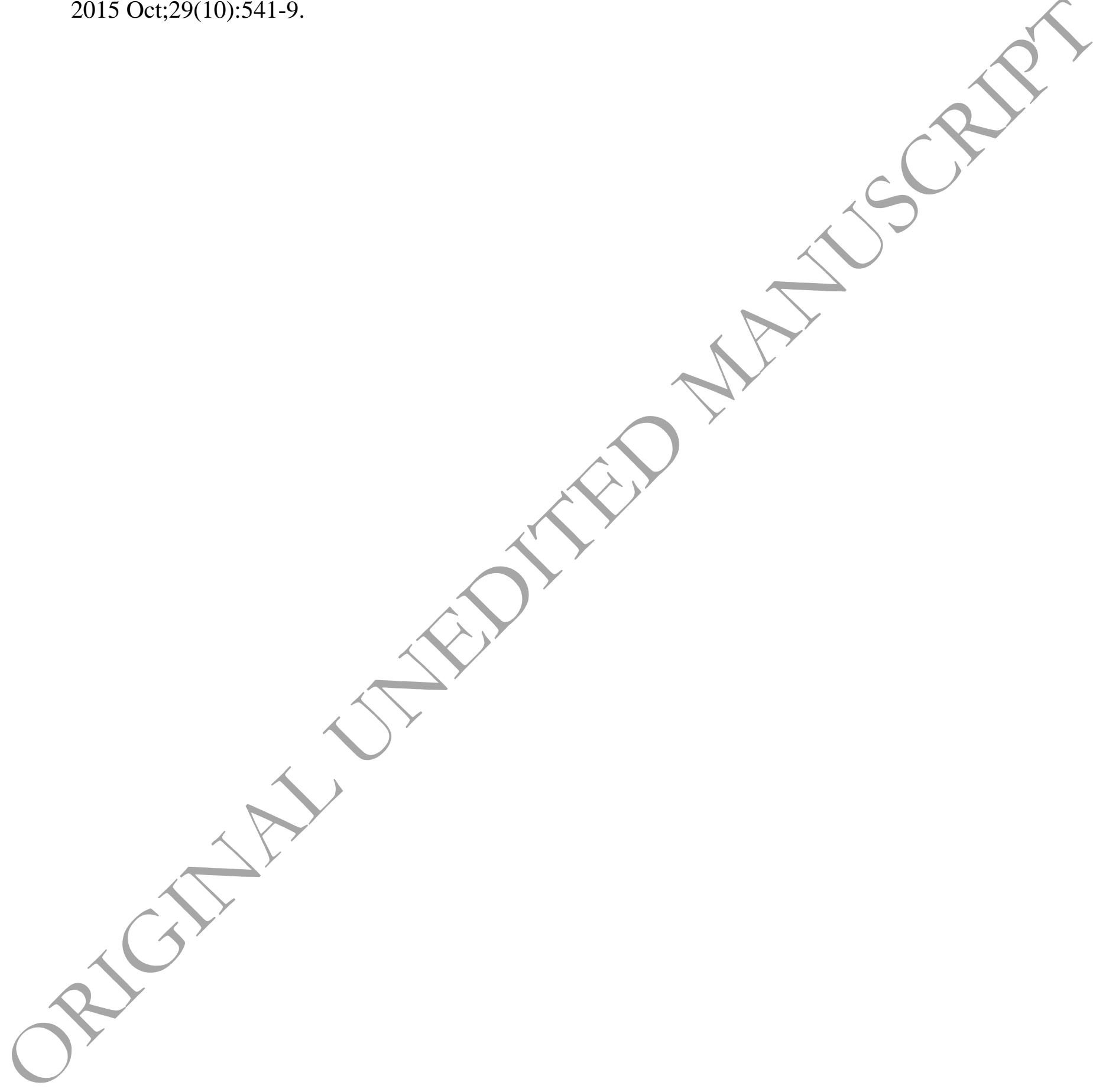


Table 1. Demographic and Clinical Characteristics of 9,229 Patients Enrolled in Care Between 2000 and 2014 in 6 Clinical Care Centers participating in the CCASAnet ${ }^{\mathrm{a}}$.

\begin{tabular}{|c|c|c|c|c|c|c|c|}
\hline Characteristics & $\begin{array}{c}\text { Site- Argentina } \\
\begin{array}{c}\text { n=1,636 } \\
\text { n }(\%)\end{array}\end{array}$ & $\begin{array}{c}\text { Site- Brazil } \\
\mathbf{n}=\mathbf{2 , 0 0 8} \\
\mathbf{n}(\%)\end{array}$ & $\begin{array}{l}\text { Site- Chile } \\
\begin{array}{c}n=1,415 \\
n(\%)\end{array}\end{array}$ & $\begin{array}{c}\text { Site- Honduras } \\
\begin{array}{c}\mathbf{n}=777 \\
\mathbf{n}(\%)\end{array}\end{array}$ & $\begin{array}{c}\text { Site- Mexico } \\
\mathbf{n}=786 \\
\hat{n}(\%)\end{array}$ & $\begin{array}{l}\text { Site- Peru } \\
\begin{array}{c}\text { n=2,607 } \\
\text { n(\%) }\end{array}\end{array}$ & $\begin{array}{c}\text { Combined } \\
\mathbf{n}=9,229 \\
\mathbf{n}(\%)\end{array}$ \\
\hline Age $(\text { years) })^{b}$ & $36(30-44)$ & $34(28-42)$ & $34(28-41)$ & $36(30-43)$ & $33(28-41)$ & $33(27-41)$ & $34(28-42)$ \\
\hline Male & $1,175(72 \%)$ & $1,435(71 \%)$ & $1,281(91 \%)$ & $433(56 \%)$ & $02(89 \%)$ & $1,926(74 \%)$ & $6,952(75 \%)$ \\
\hline $\begin{array}{l}\text { CD4 at Enrollment } \\
\left(\text { cells/uL) }{ }^{\mathrm{b}}\right.\end{array}$ & $214(81-366)$ & $292(104-507)$ & $267(96-453)$ & 3680 & $142(43-309)$ & $156(54-324)$ & $198(68-81)$ \\
\hline $\operatorname{AIDS}^{\mathrm{c}}$ & $353(22 \%)$ & $562(28 \%)$ & & $\%)$ & $432(55 \%)$ & $948(36 \%)$ & $2,941(32 \%)$ \\
\hline AIDS or $C D 4<200$ & $816(50 \%)$ & $888(44 \%)$ & & $(80 \%)$ & $560(71 \%)$ & $1,652(63 \%)$ & $5,162(56 \%)$ \\
\hline AIDS or $\mathrm{CD4}<350$ & $1,197(73 \%)$ & $1,215(61 \%)$ & & $738(95 \%)$ & $664(84 \%)$ & $2,087(80 \%)$ & $6,797(74 \%)$ \\
\hline \multicolumn{8}{|l|}{ Transmission route } \\
\hline Heterosexual & $647(40 \%)$ & & & $456(59 \%)$ & $225(29 \%)$ & $1,590(61 \%)$ & $4,160(45 \%)$ \\
\hline Homosexual & $486(30 \%)$ & & $7 \%)$ & $64(8 \%)$ & $523(67 \%)$ & $987(38 \%)$ & $3,915(42 \%)$ \\
\hline Other & $115(7 \%)$ & & $5(<1 \%)$ & $2(<1 \%)$ & $17(2 \%)$ & $23(1 \%)$ & $195(2 \%)$ \\
\hline Unknown & $388(24 \%)$ & $33(14 \%)$ & $5(<1 \%)$ & $255(33 \%)$ & $21(3 \%)$ & $7(<1 \%)$ & $959(10 \%)$ \\
\hline Patients lost to follow-up & $625(38 \%)$ & $(9 \%)$ & $187(13 \%)$ & $152(19 \%)$ & $106(13 \%)$ & $473(18 \%)$ & $1,717(19 \%)$ \\
\hline
\end{tabular}

Abbreviations: CCASAnet, Caribbean, Central and South America network for HIV epidemiology, HIV, human immunodeficiency virus, CDC, Centers for Disease Control and Prevention; WHO, World Health Organization

${ }^{a}$ Characteristics for patients included in the analysis by Caribbean, Central and South America network for HIV epidemiology (CCASAnet) site of enrollment.

${ }^{\mathrm{b}}$ Values are expressed as median (25th, 75 th percentile).

${ }^{\mathrm{c}}$ Defined on clinical grounds using CDC or WHO criteria (any stage C1, C2, C3 or WHO 4 category) 
Table 2. Attributable Risk of deaths and Fraction Attributable Population of deaths due to late presentation to care with advanced

HIV-disease delayed antiretroviral initiation among people presenting without advanced HIV-disease, and not initiating ART among those presenting to care with advanced HIV disease at one, five and ten years after enrollment in care ${ }^{\mathrm{a}}$

\begin{tabular}{|c|c|c|c|c|c|c|c|c|c|c|c|c|}
\hline & \multicolumn{6}{|c|}{ Attributable deaths } & \multicolumn{6}{|c|}{ Population Attributable Fraction } \\
\hline & \multicolumn{2}{|c|}{ Advanced-LP } & \multicolumn{2}{|c|}{$\begin{array}{c}\text { Advanced-LI } \\
\text { in people without } \\
\text { Advanced-LP }\end{array}$} & \multicolumn{2}{|c|}{$\begin{array}{c}\text { NI } \\
\text { in people with } \\
\text { Advanced-LP }\end{array}$} & \multicolumn{2}{|c|}{ Advanced-LP } & \multicolumn{2}{|c|}{$\begin{array}{l}\text { Advanced-LI } \\
\text { in people without } \\
\text { Advanced-LP }\end{array}$} & \multicolumn{2}{|c|}{$\begin{array}{c}\text { NI } \\
\text { in people with } \\
\text { Advanced-LP }\end{array}$} \\
\hline $\begin{array}{l}\text { Time after } \\
\text { enrollment }\end{array}$ & Prop & $95 \% \mathrm{CI}$ & Prop & $95 \% \mathrm{CI}$ & Prop & & & $95 \% \mathrm{CI}$ & Prop & $95 \% \mathrm{CI}$ & Prop & $95 \% \mathrm{CI}$ \\
\hline One year & 0.86 & $0.81-0.92$ & 0.39 & $0.01-0.67$ & 0.66 & & 0.78 & $0.7-0.87$ & 0.20 & $0.00-0.44$ & 0.1 & $0.06-0.17$ \\
\hline Five years & 0.71 & $0.64-0.78$ & 0.32 & $0.04-0.54$ & 0.61 & & 0.58 & $0.49-0.67$ & 0.14 & $0.01-0.28$ & 0.02 & $0.01-0.04$ \\
\hline Ten years & 0.58 & $0.47-0.69$ & 0.37 & $-0.02-0.67$ & & $b$ & 0.43 & $0.33-0.54$ & 0.15 & $0.00-0.39$ & $\mathrm{NA}^{b}$ & $\mathrm{NA}^{b}$ \\
\hline
\end{tabular}

\footnotetext{
Abbreviations:_Advanced-LP: advanced late presentation. Presentation to care with advanced HIV-disease, defined as having advanced HIV-disease at enrollment in care (defined as the first visit in each center).

Advanced HIV-disease: having AIDS or a CD4 count <200 cells/ $\mu$ L. AIDS was defined using CDC or WHO criteria (any stage C or WHO 4 category). Advanced-LI: advanced Late ART Initiation. ART initiation with advanced HIV-disease.

Prop. Proportions

${ }^{a}$ Estimations in six clinical care centers participating in the Caribbean, Central and South America network for HIV epidemiology (CCASAnet)

${ }^{b}$ Not applicable. Not estimated because most patients presenting to care with advanced HIV-disease not initiating ART did not reached 10 years of follow-up
} 
Figure 1. Distribution of patients enrolled in six HIV-care centers in Latin America participating in the Caribbean, Central and South America network for HIV epidemiology cohort (CCASAnet), according to stage of HIV-disease at enrollment and at antiretroviral treatment initiation (2001-2014).

Abbreviations: ART (combined antiretroviral therapy). LTFU (lost to follow-up). FU (Follow-up). AIDS (Acquired Immunodeficiency Syndrome)

Figure 2. Adjusted survival probability after enrollment in care in six HIV-care centers participating in the Caribbean, Central and South America network for HIV epidemiology cohort (CCASAnet), according to HIV disease stage at enrollment and at treatment initiation. (2001-2014)

\section{Abbreviations:}

Advanced-LP: Advanced Late Presentation. Presentation to care with advanced HIVdisease, defined as having AIDS or a CD 4 count $<200$ cells/ $\mu$ L. AIDS was defined using CDC or WHO criteria (any stage C or WHO 4 category).

Non-advanced LP: non-advanced Late Presentation.

Advanced-LI: advanced Late ART Initiation. ART initiation with advanced HIV-disease. Non-advanced LI. non-advanced Late Initiation

Legend: A) Advanced Late presentation vs non Advanced Late Presentation ( $n=5,162$ patients vs n=4,067 patients). B) Advanced Late Initiation vs non-advanced Late Initiation among non-advanced Late Presentation ( $n=602$ patients vs $n=3,465$ patients). C) Initiating vs non Initiating among Advanced Late Presentation ( $n=4,809$ patients vs $n=353$ patients). 


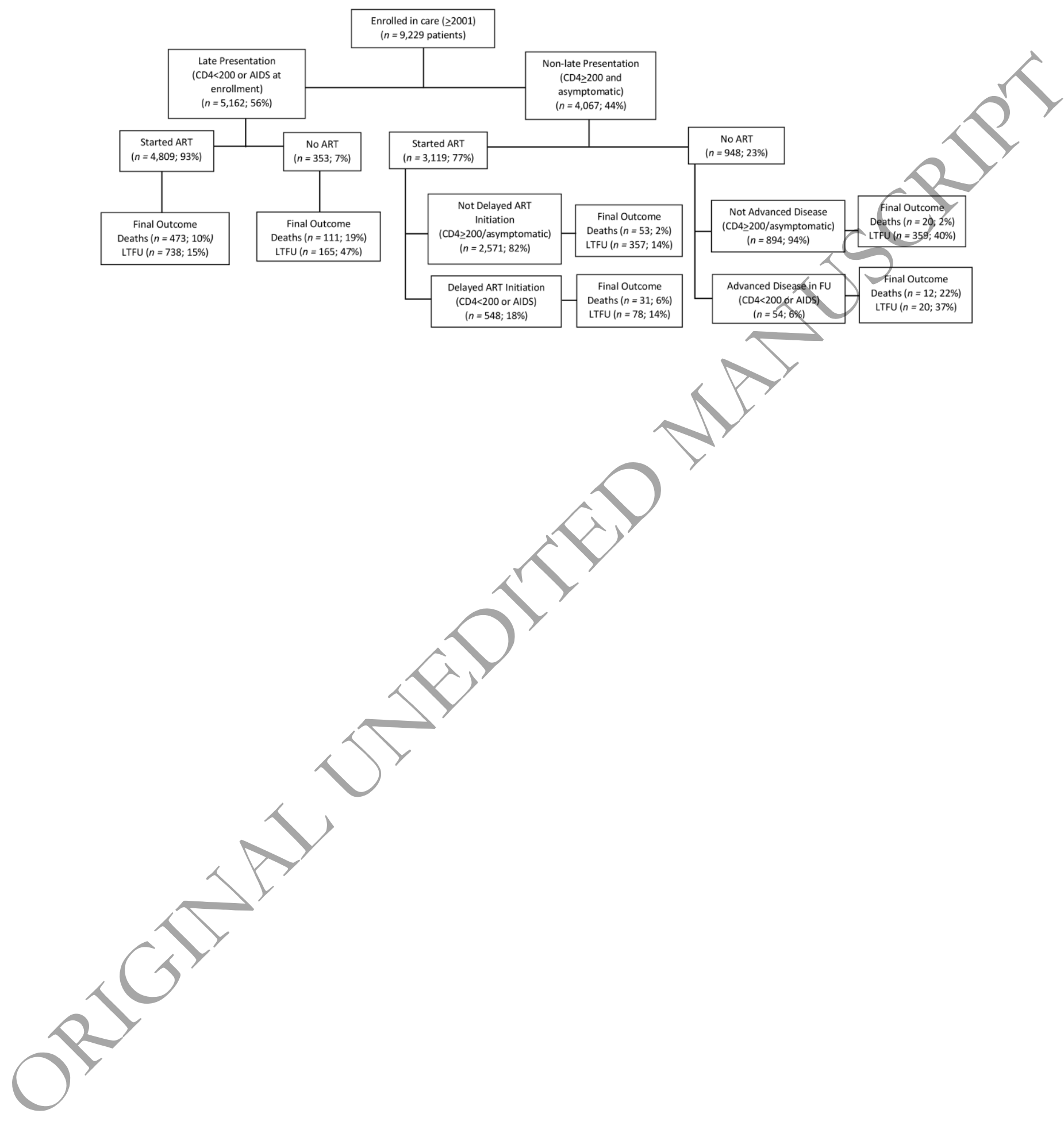


A)

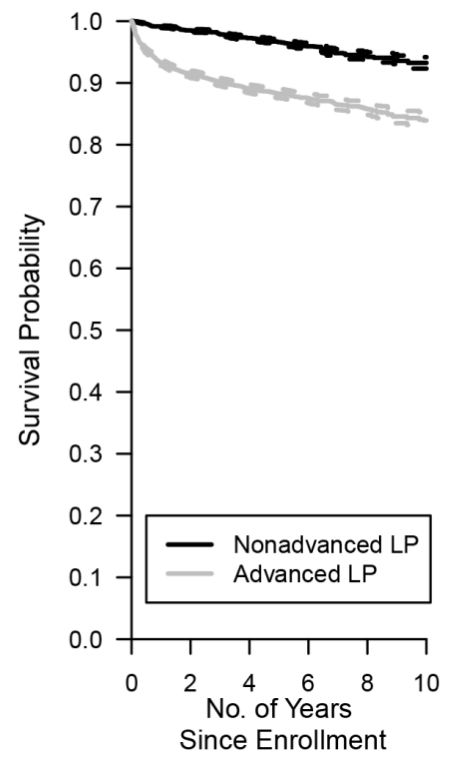

B)

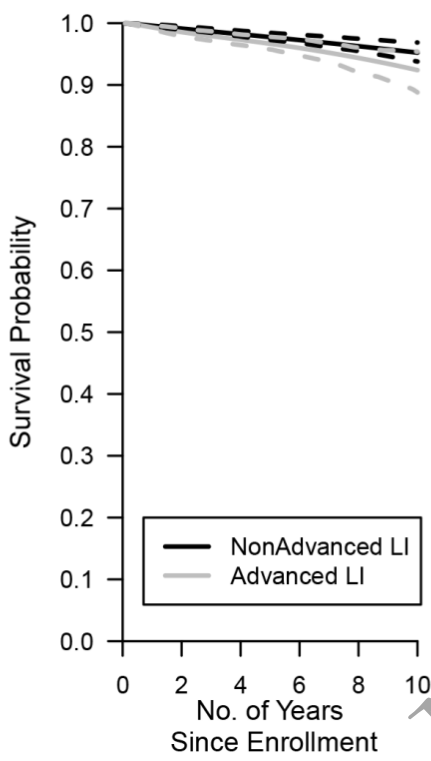

C)

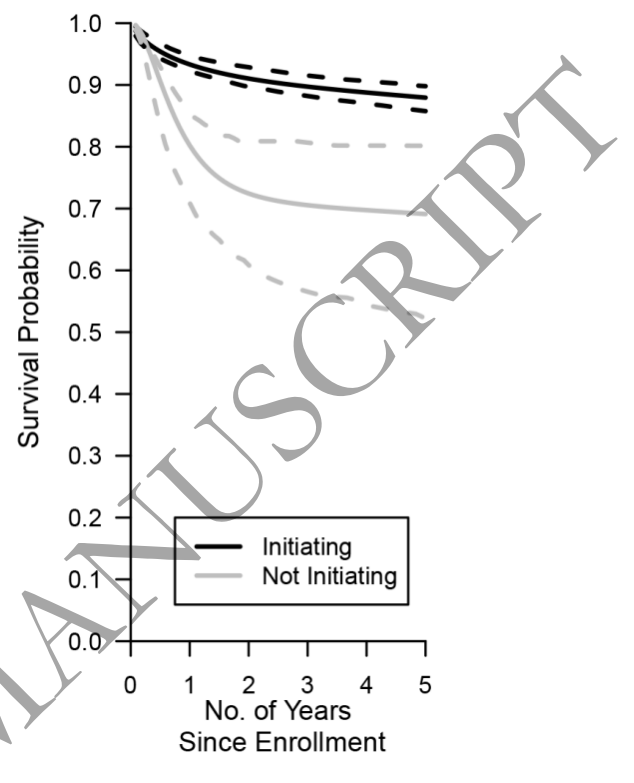

